Letter to the Editor
Pediatr Neurosurg $1997 ; 25: 325$
\begin{tabular}{|l|l|l|}
\hline D. & Douglas & Brockmeyer \\
\hline
\end{tabular}

Division of Pediatric Neurosurgery, Primary Children's Medical Center, University of Utah, Salt Lake City, Utah, USA

Concerning the article by Baumann GS et al. Pediatr Neurosurg 1996;24:193-201

\title{
Gamma Knife Radiosurgery in Children
}

Douglas Brockmeyer, MD, University of Utah School of Medicine, Primary Children's Medical Center, Division of Pediatric Neurosurgery, 100 North Medical Drive, Salt Lake City, UT 84113-110 (USA), Tel. +1 801588 3400, Fax +1 8015883409 Dear Sir,

I feel it is our responsibility as pediatric neurosurgeons to attain, analyze and pass on the best information possible to our patients and their families. Given that premise, I was surprised about the information contained within the manuscript entitled 'Gamma Knife Radiosurgery in Children' [1]. Specifically, I am referring to the 27 patients treated by gamma knife radiosurgery for arteriove-nous malformations (AVMs). Within the paper, I am most concerned about the information contained within table 3. In it, 'obliteration' rates are supplied after follow-up periods of greater than 6 months, greater than 1 year and greater than 2 years. As the authors of this paper are probably well aware, the only meaningful follow-up time after radiosurgery for AVMS is 2 years. Any AVMs that are obliterated before that time are certainly welcomed, but the 2-year obliteration rate is the accepted bench mark for this type of treatment around the world. With this in mind, the authors report 4 out of 12 patients, or $33 \%$ of patients, with complete oblitera-

tion of their AVMs. The 33\% obliteration rate is the lowest rate yet published in any series, either adult or pediatric. Of more concern is the fact that only 3 patients had angiographically confirmed complete response and 1 patient had complete response only assessed by MRI without an angiogram. Although a recent report has discussed using MRIs for follow-up of stereotactically treated AVMs, this has yet to become an accepted standard. To quote from the discussion directly, 'the ultimate obliteration rates remain to be determined' [2]. I thought articles such as these should attempt to educate us about the ultimate obliteration rates and not keep us guessing or wishing for more information. The final sentence regarding the discussion of AVMs states that their results are in contrast to surgical series where large lesions and lesions located in eloquet portions of the brain are associated with high rates of surgical morbidity. This statement is backed up with a single citation with no attempt to sample or report that broad experience of neurosurgeons in adult and pediatric AVMs throughout the world.

Most people agree that the safest method or methods possible should be used to completely obliterate AVMs in the pediatric age group. Their long-term at-risk period for hemorrhage or rebleeding is prohibitive and all efforts should be made to eradicate the lesion. I feel that an article such as this does not pass on adequate information to those who are attempting to achieve a high standard in the treatment of these lesions.

References

Baumann GS, Wara WM, Larson DA, et al: Gamma knife radiosurgery in children. Pediatr Neurosurg 1996;24:193-201. Pollack BE, Kondziolka D, Flickinger JC, Patel AK, Bissonette DJ, Lunsford LD: Magnetic resonance imaging: An accurate method to evaluate arteriovenous malformations after stereotactic radiosurgery. J Neurosurg 1996;85: 1044-1049.

KAI $\backslash$ GEI

E-Mail karger@karger.ch Fax+ 41613061234 http://www. karger. ch 
(C) 1997/S.KargerAG, Basel 1016-2291/96/0256-0325\$12.00/0 